${ }^{1}$ DDS, Master Student, School of Dentistry and Research Institute, São Leopoldo Mandic, Campinas, São Paulo, Brazil - email: ferfernandes89@hotmail.com

${ }^{2} \mathrm{PhD}$, Professor, School of Dentistry and Research Institute, São Leopoldo Mandic, Campinas, São Paulo, Brazil-email: cecilia.turssi@ gmail.com; biagomes@yahoo.com; rbasting@yahoo.com

${ }^{3} \mathrm{PhD}$, Professor, School of Dentistry and Research Institute, São Leopoldo Mandic, Campinas, São Paulo, Brazil flbamaral@gmail.com

Corresponding author:

Prof. Dr. Flávia Lucisano Botelho do Amaral

Rua José Rocha Junqueira, 13, sala 24 Ponte Preta, Campinas, SP - Brazil Zipcode 13045-775

Tel (fax): 55 (19) 32113600

Tel: 55 (19) 32113649

Received: June 26, 2017

Accepted: August 22, 2017

\section{Whitening mouthwash containing hydrogen peroxide decreases enamel microhardness in vitro}

\author{
Fernando Pelegrim Fernandes ${ }^{1}$, Cecília Pedroso \\ Turssi², Fabiana Mantovani Gomes França², Roberta \\ Tarkany Basting ${ }^{2}$, Flávia Lucisano Botelho do Amaral ${ }^{3^{\star}}$
}

Aim: To assess the effect of a mouthwash containing hydrogen peroxide (HP) on Knoop microhardness $(\mathrm{KMH})$ of bovine enamel. Methods: Fifty-one enamel slabs were polished and divided into groups ( $n=17)$, according to the product used during 28 days: HP - mouthwash containing $1,5 \%$ of HP (4 min, once/day); CP - 10\% carbamide peroxide gel (2 hours/day); AS - no treatment (kept in artificial saliva (AS). Each fragment was submitted to $\mathrm{KMH}$ test (three indentations/fragment, with a $50 \mathrm{~g}$ load for $5 \mathrm{sec}$ ) four times: before (baseline); during ( 14 and 28 days) and after ( 7 days immerged in AS) the bleaching treatment. The data were submitted to repeated-measures two-way ANOVA $(\alpha=0.05)$. Results: There was no effect of the interaction between the time and treatment factors $(p=0.327)$. No significant effect was observed from the time factor $(p=0.054)$. The factor treatment showed significant effect $(p=0.002)$. Regardless of time, the $\mathrm{KMH}$ of the enamel submitted to HP was lower than the value observed with the use of $\mathrm{CP}$, which did not differ significantly from the control group (AS). Conclusion: Although there was a trend of decreasing enamel microhardness over time, only the mouthwash containing hydrogen peroxide had a significant effect.

Keywords: Tooth Bleaching; Hydrogen Peroxide; Hardness Tests. 


\section{Introduction}

One of the most important factors for the aesthetic balance of the smile in our society is the color of our teeth, for being quickly noticed even before many other aesthetic anomalies. Tooth discoloration or stains can be located on the surface of dental enamel (extrinsic stains) or in dental structure (intrinsic stains) ${ }^{1,2}$

Extrinsic stains are obtained after the dental eruption in the oral cavity, from food or oral use products with great staining potential such as tea, coffee, tobacco, red wine, cola based beverages, etc. Intrinsic stains have a multifactorial etiology, both pre-and post-eruptive ${ }^{3}$. In vital teeth, discoloration can be natural (teeth with yellow or gray shades), caused by the ingestion of tetracycline or fluoride, or defects of congenital formations (amelogenesis and dentinogenesis imperfecta) ${ }^{4,5}$.

Dental bleaching is being a highly requested procedure by patients seeking cosmetic dentistry resources as a result of a poor aesthetic, caused by dental discoloration ${ }^{6,7}$. Hydrogen peroxide has been used for dental bleaching in the late 1800s, firstly with the aim of removing pigments from non vital and later from vital teeth ${ }^{8}$. Hydrogen peroxide is a vehicle of oxygen radical, which promotes oxidation and reduction of pigments. These pigments are fractionated in to smaller molecular chains, being entirely or partially removed from the dental structure by diffusion?.

For vital teeth, the techniques are the in-office technique, the over-the-counter bleaching, and the home-use nightguard vital bleaching technique, being each technique driven by different peroxide concentrations, time and mode of whitening product application. The home-use technique consists in applying a 10 or $16 \%$ carbamide peroxide gel that can be applied every night for 6 to 8 hours, or during the day, for one or 2 hours, with less tooth sensitivity within the decreased application time ${ }^{10}$. In the in-office technique the soft tissues are protected, and a hydrogen peroxide gel in a higher concentration is applied several times in a short period of time over the dental surface ${ }^{8}$.

The over-the-counter technique uses products that are bought in supermarkets or drugstores, such as bleaching toothpastes and mouthwashes, aimed to whiten teeth in short periods of time with a low cost. These mouthwashes have in addition to water, antimicrobials, salts, and sometimes alcohol, and also contain hydrogen peroxide in its composition ${ }^{11}$, but in lower peroxide concentrations (around 1,5\%) than those observed in in-office and home-use gels. Although the effectiveness of over-the-counter products in dental bleaching has been reposted, it is less than the one obtained from home-use carbamide peroxide at $10 \%{ }^{12}$. Besides this, controversies are known about the effects of bleaching agents on the microhardness of dental structures, especially the enamel ${ }^{13}$.

The over-the-counter products has been known to reduce the hardness of dental enamel ${ }^{14}$ and resin composites ${ }^{15}$ when used for 14 days, depending on the trade mark being used, and whether or not the product contains hydrogen peroxide (active component). The literature is still scarce to affirm the relation of mouthwashes recently launched on the market, which contains the bleaching agent (hydrogen peroxide) with the possible loss of minerals, and consequently a decrease of enamel microhardness. 
This issue is especially important if one considers that patients can use this product without the supervision of a professional and that manufacturer indicate that they can be used for 28 consecutive days, a relatively long time.

Considering that peroxide-containing mouthwashes are available for purchase without the need of a dentist recommendation and that they can affect enamel structure in someway, it is necessary to conduct experimental studies to verify this possible association. Thus, the aim of this study was to monitor the effect of a mouthwash containing $1.5 \%$ of hydrogen peroxide, compared to $10 \%$ carbamide peroxide gel, by means of Knoop microhardness test in bovine enamel, in the treatment periods (for 28 days) and post-bleaching (7 days). The null hypothesis was that neither bleaching agents nor treatment periods would affect enamel Knoop microhardness.

\section{Materials and Methods}

Ethical aspects - This study was approved by the Animal Research Ethical Committee (protocol \#2013/0143).

\section{Experimental Design}

The factors under study were the bleaching agents, at three levels, and times of treatment, at four levels:

1. Treatment agents:

CP $-10 \%$ carbamide peroxide.

HP - Mouthwash containing 1.5\% hydrogen peroxide.

AS - Artificial saliva

2. Evaluation times: before (baseline), during (14 days) and after (28 days) the bleaching treatment, 7 days of post- treatment.

The experimental units were composed of 51 enamel slabs randomly distributed into the three levels of treatment agents $(n=17)$. The response variables were Knoop microhardness $(\mathrm{KMH})$. Analysis in each period was performed in the same specimen, which consisted of a block.

The bleaching agents, as well as the artificial saliva, are shown in Table 1.

\section{Preparation of Dental Slabs}

In this experiment, 51 bovine incisors stored in thymol $(0.1 \%, \mathrm{pH} 7.0)$ were used. The teeth were debrided with scalpel blades and periodontal curettes and had their roots separate from the dental crowns using a diamond disc of high concentration (Extec Corp, Enfield, CT, EUA) in a precision cutter (Isomet 1000, Buehler Lake Bluff, Illinois, EUA). Longitudinal sections were cut to obtain $3 \mathrm{~mm} \times 3 \mathrm{~mm}$ enamel slabs, and those with stains or cracks were excluded after visual observation under a stereomicroscope loupe (EK3S3, São Paulo, São Paulo, Brazil) at 30x magnification.

The enamel slabs were embedded in polyester resin (Maxi Rubber Ind Quím LTDA. Diadema/SP/Brazil) in 2.0-cm diameter polyvinyl chloride (PVC) molds, leaving the exter- 
nal surface of dental uncovered by resin. After 24 hours, the specimens were removed from the molds and flattened in a pneumatic polishing machine (Ecomet/Automet 250, Buehler, Lake Bluff, II, EUA) with decreasing granulations (400, 600 and 1.200) (Arotec S/A Ind e Comércio São Paulo/SP/Brazil) of abrasive paper under water cooling, and cleaned in a Ultrasonic washer (Unique Ind. e Com, de Prod. Elet. LTDA Model: USC 1400 São Paulo/SP/Brazil) after each granulation and polished with Diamond paste (Arotec Granulation: $6 \mu \mathrm{m} / 3 \mu \mathrm{m} / 1 \mu \mathrm{m} /{ }^{1} / 4 \mu \mathrm{m}$ São Paulo/SP/Brazil) on felt discs (Arotec São Paulo/SP/Brazil).

Before (baseline), during (14 and 28 days) and 7 days after the treatment, all specimens were submitted to the microhardness tests, using a microhardness tester (PanTec Digital microhardness tester HVS-1000/Panambra, São Paulo, São Paulo, Brazil) with a Knoop penetrator, performing three indentations with a $50-g$ load for 5 seconds. As $\mathrm{KMH}$ is a non-destructive testing, analysis in each period was performed in the same specimen.

\section{Treatment agent procedures}

The treatment agents used in this study were described in Table 1, according to composition, manufacturer and $\mathrm{pH}$ values.

Group CP: 10\% Carbamide peroxide gel (Opalescense PF, Brazil's Ultradent, Indaiatuba, São Paulo, Brazil), simulating the home-use bleaching, applying $0.02 \mathrm{~mL}$ of the product over each specimen for two hours/day ${ }^{12}$. Then they were rinsed with distilled water and stored in $5 \mathrm{~mL}$ of artificial saliva, and kept in a bacteriological stove (Odontobrás Ind. e Com. Equip. Med. Odont. LTDA Model: ECB 1.3 digital, Ribeirão Preto/SP/Brazil), at $37^{\circ} \mathrm{C}$. This procedure was repeated for four weeks. Hypodermic syringes were used for the accuracy of quantity of gel over each fragment.

Group HP: The specimens were immersed in the mouthwash containing 1.5\% hydrogen peroxide (Colgate Plax Whitening, Colgate Palmolive Ind e Comércio Ltda. S.B. Campo/SP, Brazil), for four minutes, once a day, each specimen were submerged in

Table 1. Products used in the experiment.

\begin{tabular}{|c|c|c|c|c|}
\hline Materials & Manufacturer & $\begin{array}{l}\text { Batch } \\
\text { Number }\end{array}$ & Composition & $\mathrm{pH}$ \\
\hline $\begin{array}{l}\text { Opalescence PF } 10 \% \\
\text { CP }\end{array}$ & $\begin{array}{c}\text { Ultradent dental } \\
\text { products Ltda. } \\
\text { Indaiatuba/SP- } \\
\text { Brazil }\end{array}$ & B95ZN & $\begin{array}{c}10 \% \text { Carbamide Peroxide, } 0.5 \% \\
\text { Potassium nitrate and } 0.11 \% \\
\text { fluoride ions }\end{array}$ & 6.8 \\
\hline $\begin{array}{l}\text { Colgate Plax Whitening } \\
\text { HP }\end{array}$ & $\begin{array}{l}\text { Colgate Palmolive } \\
\text { S.B. Campo/SP, } \\
\text { Brazil }\end{array}$ & $\begin{array}{l}\text { BR122A } \\
\text { BR1210 } \\
\text { BR121A }\end{array}$ & $\begin{array}{l}\text { Water, sorbitol, ethyl alcohol, } \\
1.5 \% \text { hydrogen peroxide, } \\
\text { poloxamer } 338, \text { polysorbate } \\
20, \text { methyl silicate, menthol, } \\
\text { sodium saccharin, cl } 42090\end{array}$ & $3.4^{*}$ \\
\hline $\begin{array}{l}\text { Artificial saliva described } \\
\text { by Featherstone et al. }{ }^{18} \text { and } \\
\text { modified by Serra \& Cury }{ }^{19} \text { AS }\end{array}$ & - & - & $\begin{array}{l}\text { 1.5mM Ca, } 0.9 \text { mM P, buffer } \\
\text { TRIS } 20 \text { mM, } 150 \text { mM KCl }\end{array}$ & 7.0 \\
\hline
\end{tabular}

* Measured in laboratory, in triplicate. 
$4 \mathrm{~mL}$ of the solution and subjected to agitation on an agitator platform (Cientec ${ }^{\circledR}$, CT 158) simulating a mouth rinse, and rinsed with distilled water after the procedure and immersed in $5 \mathrm{~mL}$ of artificial saliva, kept in a bacteriological stove (Odontobrás Ind. e Com. Equip. Med. Odont. LTDA Model: ECB 1.3 digital, Ribeirão Preto/SP/Brazil), at $37^{\circ} \mathrm{C}$. This procedure was repeated for four weeks.

Group AS: No bleaching agent was applied, the specimens were kept in $5 \mathrm{~mL}$ of artificial saliva that were renewed in every two days and the specimens were rinsed with distilled water and kept in a bacteriological stove (Odontobrás Ind. e Com. Equip. Med. Odont. LTDA Model: ECB 1.3 digital, Ribeirão Preto, SP, Brazil), at $37^{\circ} \mathrm{C}$. There was no evident calculus or material over specimens stored in saliva for 28 days.

\section{Post-Treatment Period}

After the treatment, the fragments were kept in their individual receptacles with $5 \mathrm{~mL}$ of artificial saliva, in a bacteriological stove (Odontobrás Ind. e Com. Equip. Med. Odont. LTDA Model: ECB 1.3 digital, Ribeirão Preto/SP/Brazil), at $37^{\circ} \mathrm{C}$ for 7 days to evaluate the post- treatment period and a possible remineralizing effect of this solution. The solution was changed every two days. Knoop microhardness was also measured after 7 days of post-treatment.

\section{Statistical Analysis}

After checking normality (Kolmogorov-Smirnov; $p>0.05$ ) and homoscedasticity (Levene; $p>0.05$ ) of data, the repeated measures two-way analysis of variance was performed, followed by Tukey's test for multiple comparisons. Statistical calculations were performed with SPSS 20 (SPSS Inc., Chicago, IL, USA). The significance level was set at $5 \%$.

\section{Results}

Table 2 shows the averages and standard deviations of Knoop microhardness for the tested groups, in different times. The two-way analysis of variance for repeated measurements showed no significant interaction between the factors under study $(p=0.327)$. No significant effect was observed from the time factor $(p=0.054)$. The treatment factor showed significant effect ( $p=0.002)$. Tukey's test revealed that regardless of time, the microhardness mean of the enamel submitted to HP treatment was lower than that observed with the use of $\mathrm{CP}$, which did not differ significantly from

Table 2. Averages and standard deviations of Knoop microhardness for the groups tested, in different times.

\begin{tabular}{lccccc}
\hline & Baseline & $\begin{array}{c}\text { 14 days of } \\
\text { treatment }\end{array}$ & $\begin{array}{c}\text { 28 days of } \\
\text { treatment }\end{array}$ & $\begin{array}{c}\text { 07 days of } \\
\text { post-treatment }\end{array}$ & Grand Mean \\
\hline $\mathrm{CP}$ & $351(43)$ & $331(28)$ & $333(26)$ & $335(41)$ & $337(35) \mathrm{A}$ \\
\hline $\mathrm{HP}$ & $317(55)$ & $279(50)$ & $251(46)$ & $293(41)$ & 285(55)B \\
\hline Saliva & $338(57)$ & $329(46)$ & $316(44)$ & $325(42)$ & $327(47) \mathrm{A}$ \\
\hline Grand Mean & $335(53) \mathrm{a}$ & $313(48) \mathrm{a}$ & $300(52) \mathrm{a}$ & $318(47) \mathrm{a}$ & \\
\hline
\end{tabular}

Grand means followed by distinct letters statistically differ between each other (lowercase compare times and uppercase compare treatments) 
the control group (artificial saliva). Figure 1 illustrates a line chart of Knoop microhardness of experimental groups over time. It can be observed that although there was a trend of decrease in microhardness within time, no statistical difference was observed among the different periods of evaluation.

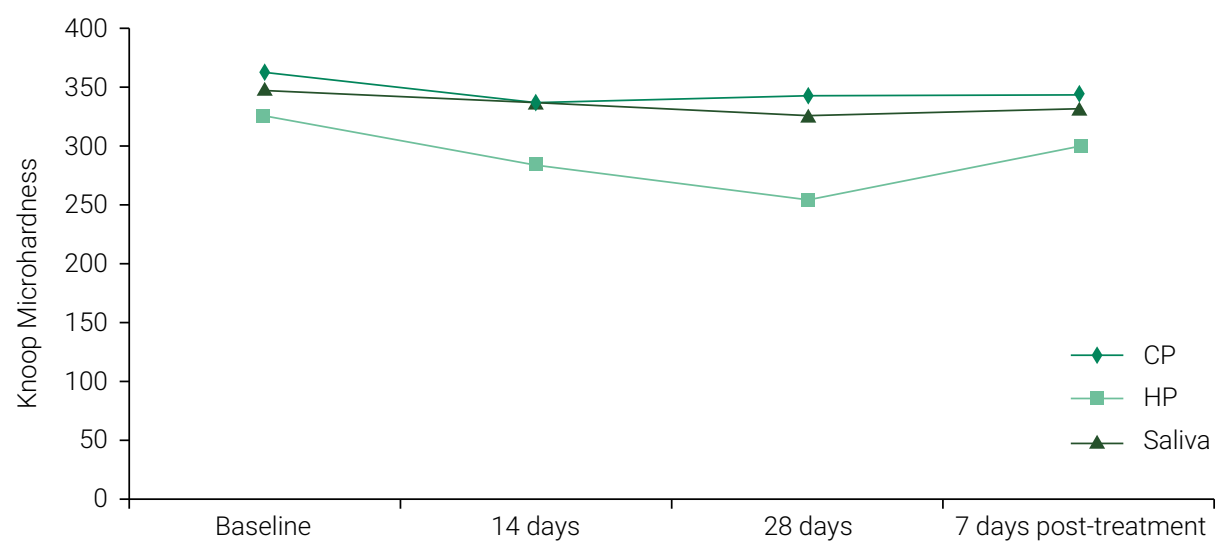

Figure 1. Chart representing Knoop microhardness of experimental groups over time.

\section{Discussion}

The present in vitro study assessed the effect of a mouthwash containing $1.5 \%$ of hydrogen peroxide as an active component in its composition on bovine enamel surface microhardness and compared with $10 \%$ carbamide peroxide.

The results obtained by microhardness analysis showed that the specimens of bovine enamel submitted to whitening mouthwash had smaller microhardness values compared to those submitted to $10 \%$ carbamide peroxide gel. Therefore, the null hypothesis was rejected.

The $\mathrm{pH}$ of the products used were measured and showed the result of 6.8 to the whitening gel and 3.4 for the whitening mouthwash. It can be assumed that the low pH of the whitening mouthwash may have acted on the demineralization of enamel surface favoring the decrease of microhardness, since the $\mathrm{pH}$ value is less than the enamel critical pH (5.5). In fact, Lima et al. ${ }^{16}$ (2013) demonstrated, by 3D scanning eletronic microscopy, the erosive potential of Plax Whitening associated with toothbrushing.

These results are similar to previous studies which also verified reduction of dental enamel microhardness ${ }^{14}$ and resin composite ${ }^{15}$ with the use of whitening mouthwashes. It would be interesting to investigate the effect of such products on the morphology of dental enamel by means of scanning electron microscopy and atomic force microscopy, however, literature is still scarce in these evaluations and should be considered in further studies.

Also, the manufacturer of the mouthwash recommends that the product should be used for 1 minute before and 1 minute after brushing the teeth, twice a day, totaling 4 minutes a day. In the present research, brushing was not considered so that only 
the whitening mouthwash effect was observed. It is speculated that the application of mouthwashes in association with brushing could have brought different results, as the literature has demonstrated that this association may cause enamel loss ${ }^{16}$. On the other hand, the prolonged immersion time (4 consecutives minutes) can also have exacerbated the results in a more significative manner than fractioning the immersions two times a day, with storage of specimens in saliva between cycles. Having this in mind, Potgieter et al. (2014) ${ }^{17}$ demonstrated no statistical reduction in enamel microhardness when Plax whitening was applied twice a day, for 1 minute in each immersion, although they did not perform toothbrushing.

On the other hand, the use of the whitening gel containing $10 \%$ of carbamide peroxide did not influence significantly on the bovine enamel microhardness, a fact that may be related to the presence of fluoride ions in its composition, in addition to the $\mathrm{pH}$ value, greater than the critical $\mathrm{pH}$ for demineralization of dental enamel. In fact, Cavalli et al. ${ }^{18}$ (2010) showed that the presence of fluoride in the composition of the carbamide peroxide based whitening gel minimized the loss of ions of the dental surface. In a literature review of Attin et al. ${ }^{19}$ (2009) it was observed that $49 \%$ of the in vitro studies reviewed did not show microhardness reduction over time with the use of home-use bleaching agents. Previous experimental studies had similar results to those found in the present study ${ }^{20,21}$. Perhaps, the effects of carbamide peroxide gel on the dental structures may also be related to the time of gel in contact with dental structure. The manufacturer indicates the use of $10 \%$ carbamide peroxide gel for 8 hours, but, in the present study, the protocol of 2 hours of application was choosed because this time prooved to sufficiently bleach enamel ${ }^{12}$, reduce tooth sensitivity ${ }^{10}$, while does not affect the concentration of enamel minerals, assessed with the technique of enamel microbiopsy 22 . Thus, if the manufacturer's instructions were strictly followed, different results could be achieved.

The results of this study also demonstrated that, although there was a tendency of decrease in microhardness values for the time of 28 days, there was no significant difference in the evaluated times, when considered in conjunction with the bleaching treatments. This may have been attributed due to the presence of artificial saliva in all groups, which may have leveled the results of microhardness for being a ion supersaturated solution ${ }^{23}$ that favors the absorption and precipitation of salivary components, such as calcium and phosphate ${ }^{24}$.

Although it has been reported the effectiveness of OTC products to whiten dental enamel ${ }^{12},{ }^{25}$ the present study demonstrated reduction in bovine dental enamel microhardness after using the mouthwash containing $1.5 \%$ of hydrogen peroxide, showing that such product should be used with caution, especially if considered the carcinogenic potential that such products may have ${ }^{26}$. Still, literature is scarce regarding the effects of such products on the mineral loss of tooth structure, requiring, therefore, more studies on this subject, mainly in situ studies and clinical trials. Also, the use of OTC whitening mouthwashes in conjunction with toothbrushing should be evaluated in further studies.

This study concluded that although there was a trend of decreasing microhardness values over time, only the whitening mouthwash containing hydrogen peroxide had a significant effect. 


\section{References}

1. Alqahtani MQ. Tooth-bleaching procedures and their controversial effects: a literature review. Saudi Dent J. 2014 Apr;26(2):33-46. doi: 10.1016/j.sdentj.2014.02.002.

2. Nathoo AS. The chemistry and mechanisms of extrinsic and intrinsic discoloration. J Am Dent Assoc. 1997 Apr;128 Suppl:6S-10S.

3. Price RB, Loney RW, Doyle MG, Moulding MB. An evaluation of a technique to remove stains from teeth using microabrasion. J Am Dent Assoc. 2003 Aug;134(8):1066-71.

4. Watts A, Addy M. Tooth discolouration and staining: a review of the literature. Br Dent J. 2001 Mar 24;190(6):309-16.

5. Sundfeld RH, Croll TP, Briso AL, Alexandre RS, Sundfeld Neto D. Considerations about enamel microabrasion after 18 years. Am J Dent. 2007 Apr;20(2):67-72.

6. Sheoran N, Garg S, Damle SG, Dhindsa A, Opal S, Gupta S. Esthetic management of developmental enamel opacities in young permanent maxillary incisors with two microabrasion techniques - a split mouth study. J Esthet Restor Dent. 2014 Sep-Oct;26(5):345-52. doi: 10.1111/jerd.12096.

7. Parreiras SO, Vianna P, Kossatz S, Loguercio AD, Reis A. Effects of light activated in-office bleaching on permeability, microhardness, and mineral content of enamel. Oper Dent. 2014 Sep-Oct;39(5):E225-30. doi: 10.2341/13-031-L.

8. Haywood VB. History, safety, and effectiveness of current bleaching techniques and applications of the nightguard vital bleaching technique. Quintessence Int. 1992 Jul;23(7):471-88.

9. Eimar H, Siciliano R, Abdallah MN, Nader SA, Amin WM, Martinez PP, et al. Hydrogen peroxide whitens teeth by oxidizing the organic structure. J Dent. 2012 Dec;40 Suppl 2:e25-33. doi: 10.1016/j.jdent.2012.08.008.

10. Cardoso PC, Reis A, Loguercio A, Vieira LC, Baratieri LN. Clinical effectiveness and tooth sensitivity associated with different bleaching times for a 10 percent carbamide peroxide gel. J Am Dent Assoc. 2010 Oct;141(10):1213-20.

11. Moran JM. Chemical plaque control-prevention for the masses. Periodontol 2000. 1997 Oct;15:109-17.

12. Jaime IM, França FM, Basting RT, Turssi CP, Amaral FL. Efficacy of hydrogen-peroxide-based mouthwash in altering enamel color. Am J Dent. 2014 Feb;27(1):47-50.

13. Borges BC, Borges JS, de Melo CD, Pinheiro IV, Santos AJ, Braz R et al. Efficacy of a novel at-home bleaching technique with carbamide peroxides modified by CPP-ACP and its effect on the microhardness of bleached enamel. Oper Dent. 2011 Sep-Oct;36(5):521-8. doi: 10.2341/11-013-L.

14. Majeed A, Grobler SR, Moola MH, Oberholzer TG. Effect of four over-the-counter tooth-whitening products on enamel microhardness. SADJ. 2011 Oct;66(9):412-5.

15. Miranda Dde A, Bertoldo CE, Aguiar FH, Lima DA, Lovadino JR. Effects of mouthwashes on Knoop hardness and surface roughness of dental composites after different immersion times. Braz Oral Res. 2011 Mar-Apr;25(2):168-73.

16. Lima JP, Melo MA, Passos VF, Braga CL, Rodrigues LK, Santiago SL. Dentin erosion by whitening mouthwash associated to toothbrushing abrasion: a focus variation 3D scanning microscopy study. Microsc Res Tech. 2013 Sep;76(9):904-8. doi: 10.1002/jemt.22246.

17. Potgieter E, Osman Y, Grobler SR. The effect of three whitening oral rinses on enamel micro-hardness. SADJ. 2014 May;69(4):152, 154-6.

18. Cavalli V, Rodrigues LK, Paes-Leme AF, Brancalion ML, Arruda MA, Berger SB et al. Effects of bleaching agents containing fluoride and calcium on human enamel. Quintessence Int. 2010 Sep;41(8):e157-65.

19. Attin T, Schmidlin PR, Wegehaupt F, Wiegand A. Influence of study design on the impact of bleaching agents on dental enamel microhardness: a review. Dent Mater. 2009 Feb;25(2):143-57. doi: 10.1016/j.dental.2008.05.010. 
20. Maia E, Baratieri LN, Caldeira de Andrada MA, Monteiro S Jr, Vieira LC. The influence of two home-applied bleaching agents on enamel microhardness: an in situ study. J Dent. 2008 Jan;36(1):2-7.

21. Abouassi T, Wolkewitz M, Hahn P. Effect of carbamide peroxide and hydrogen peroxide on enamel surface: an in vitro study. Clin Oral Investig. 2011 Oct;15(5):673-80. doi: 10.1007/s00784-010-0439-1.

22. Amaral FL, Sasaki RT, da Silva TC, França FM, Flório FM, Basting RT. The effects of home-use and in-office bleaching treatments on calcium and phosphorus concentrations in tooth enamel: an in vivo study. J Am Dent Assoc. 2012 Jun;143(6):580-6.

23. Freitas PM, Turssi CP, Hara AT, Serra MC. Dentin microhardness during and after whitening treatments. Quintessence Int. 2004 May;35(5):411-7.

24. Araujo Fde O, Baratieri LN, Araújo E. In situ study of in-office bleaching procedures using light sources on human enamel microhardness. Oper Dent. 2010 Mar-Apr;35(2):139-46. doi: 10.2341/08-033-C.

25. Oliveira J, Sarlo RS, Bresciani E, Caneppele T. Whitening Efficacy of Whitening Mouth Rinses Used Alone or in Conjunction With Carbamide Peroxide Home Whitening. Oper Dent. 2017 May/Jun;42(3):319-326. doi: 10.2341/15-361-L.

26. Carlin V, Matsumoto MA, Saraiva PP, Artioli A, Oshima CT, Ribeiro DA. Cytogenetic damage induced by mouthrinses formulations in vivo and in vitro. Clin Oral Investig. 2012 Jun;16(3):813-20. doi: 10.1007/s00784-011-0559-2. 